\title{
(E)-1-(2-Aminophenyl)-3- (benzo[d][1,3]dioxol-5-yl)prop-2-en-1-one
}

\author{
Rodrigo Abonia ${ }^{1, *}$, Diana Arteaga ${ }^{1}$, Daniel Insuasty ${ }^{1}$, Jairo Quiroga ${ }^{1}$, Braulio Insuasty ${ }^{1}$, \\ Rodolfo Moreno-Fuquen ${ }^{1}$ and Alan R. Kennedy ${ }^{2}$ \\ 1 Department of Chemistry, Universidad del Valle, A.A. 25360 Santiago de Cali, Colombia; \\ diana.arteaga@correounivalle.edu.co (D.A.); daniel.insuasty@correounivalle.edu.co (D.I.); \\ jairo.quiroga@correounivalle.edu.co (J.Q.); braulio.insuasty@correounivalle.edu.co (B.I.); \\ rodimo26@yahoo.es (R.M-F.) \\ 2 WestCHEM, Department of Pure and Applied Chemistry, University of Strathclyde, \\ 295 Cathedral Street, Glasgow G1 1XL, Scotland; a.r.kennedy@strath.ac.uk \\ * Correspondence: rodrigo.abonia@correounivalle.edu.co; Tel.: +57-2-339-3248
}

Academic Editor: René T. Boeré

Received: 1 December 2016; Accepted: 28 December 2016; Published: 30 December 2016

\begin{abstract}
The title chalcone (E)-1-(2-aminophenyl)-3-(benzo[d][1,3]dioxol-5-yl)prop-2-en-1-one was obtained in $76 \%$ yield from a $\mathrm{NaOH}$ catalyzed Claisen-Schmidt condensation reaction between $o$-aminoacetophenone and piperonal. This product will be used as a key precursor for the development of an alternative route for the total synthesis of the alkaloid Graveoline. Single crystals of the title compound suitable for X-ray diffraction were grown via slow evaporation in ethanol at room temperature. A complete crystallographic study was performed in depth to unequivocally confirm its structure. The crystal structure of the title $o$-aminochalcone, $\mathrm{C}_{16} \mathrm{H}_{13} \mathrm{NO}_{3}$, shows two molecules per asymmetric unit $(\mathrm{Z}=4)$ and adopts an $E$ configuration about the $\mathrm{C}=\mathrm{C}$ double bond. In the title compound, the mean plane of the non- $\mathrm{H}$ atoms of the central chalcone fragment $\mathrm{C}-\mathrm{C}(\mathrm{O})-\mathrm{C}-\mathrm{C}-\mathrm{C}$ is as follow: [root-mean-square (r.m.s.) deviation $=0.0210 \AA$ for $\mathrm{A}-\mathrm{B}$ and 0.0493 for C-D molecules] In the crystal, molecules are linked by $\mathrm{N}-\mathrm{H} . . . \mathrm{O}$ and $\mathrm{C}-\mathrm{H} . . . \mathrm{O}$, hydrogen bonds forming $\mathrm{S}(6), \mathrm{R}^{2}{ }_{2}(6)$ and edge-fused $\mathrm{R}_{4}^{4}$ (24)rings along with $\mathrm{C}(18)$ chains running parallel to (110).
\end{abstract}

Keywords: $o$-aminoacetophenones; benzodioxolyl moiety; Claisen-Schmidt condensation; $o$-aminochalcones; single crystal X-ray diffraction

\section{Introduction}

Chalcones are synthetic or naturally occurring $\alpha, \beta$-unsaturated diaryl ketones which have shown a wide spectrum of biological [1-4] and synthetic [5,6] properties. It has been found that their biological activities and those of their derivatives may be enhanced by the insertion of heterocyclic rings in their structures [7]. Thus, chalcones bearing the heterocyclic [1,3]-dioxolo functionality are of particular interest because diverse synthetic and natural compounds containing this functionality in their frameworks have displayed important biological and pharmacological properties [8,9]. Continuing with our current studies on the synthetic utility of $o$-aminochalcones [10,11], the amino-[1,3]-dioxolo derivative 3 was obtained (as precursor for alkaloid Graveoline), from the condensation reaction of $o$-aminoacetophenone 1 and piperonal 2 in ethanolic alkaline media, (Scheme 1).

\section{Results and Discussion}

Chalcone 3 was previously prepared in $82 \%$ yield (m.p. $112{ }^{\circ} \mathrm{C}$ ) by Tókés and Forró [12] for diverse bromination studies involving the formation of the tetrahydroquinolone 4, (Entry 1, Scheme 1). Posteriorly, Bunce and Nammalwar [13] obtained chalcone 3 as a side-product in $46 \%$ yield 
(m.p. $110-112{ }^{\circ} \mathrm{C}$ ), attempting to synthesize the quinolone 4 through an in situ tandem reduction-Michael addition reaction in acetic acid media, (Entry 2, Scheme 1).

In this work, compound 3 was synthesized as a key intermediate for an alternative route of synthesis of alkaloid Graveoline and related methylenedioxy 2-aryl-4-quinolones. This product was obtained in $76 \%$ yield from equimolar amounts of $o$-aminoacetophenone 1 and piperonal 2 via a $\mathrm{NaOH}$ catalyzed Claisen-Schmidt condensation reaction as shown in Scheme 1, Entry 3. The residue was crystallized from ethanol affording a yellow solid. Single crystals of $\mathbf{3}$ suitable for X-ray diffraction were grown via slow evaporation of the ethanolic mother liquor.

\section{Previous work:}

Entry 1. (Tókés and Forró [12])

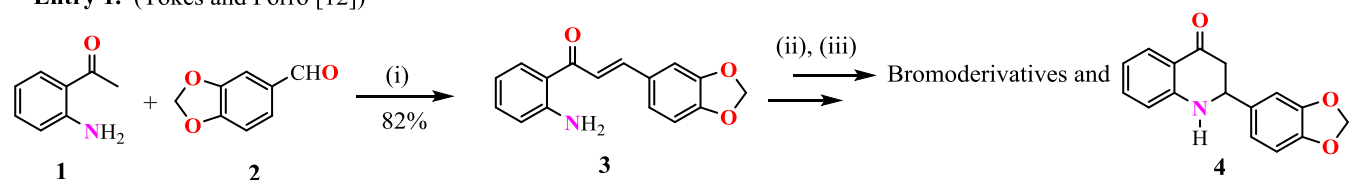

Entry 2. (Bunce and Nammalwar [13])

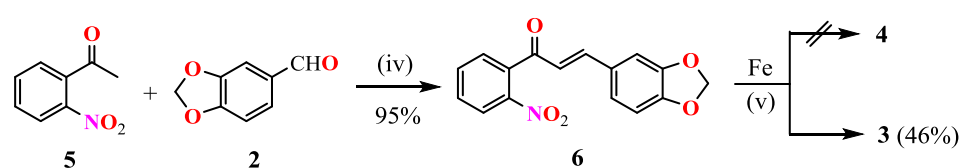

(i) $=\mathrm{KOH}, \mathrm{EtOH}, \mathrm{rt}, 12 \mathrm{~h}$; (ii) $=\mathrm{Br}_{2}, \mathrm{CHCl}_{3}$, rt or NBS, $\mathrm{MeOH}$; (iii) $=\mathrm{AcOH}-\mathrm{H}_{3} \mathrm{PO}_{4}, 100^{\circ} \mathrm{C}$; (iv) $=\mathrm{NaOH}, \mathrm{EtOH}, 0{ }^{\circ} \mathrm{C} ; \quad(\mathrm{v})=\mathrm{AcOH}, 115^{\circ} \mathrm{C}$

This work:

Entry 3.

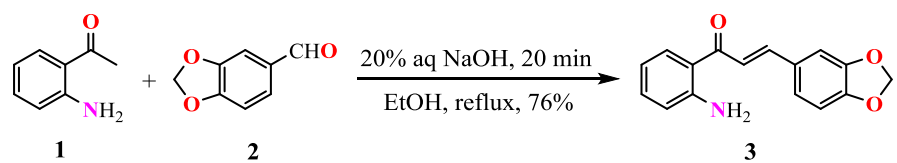

Scheme 1. Routes for the synthesis of the $o$-aminochalcone 3.

Although compound 3 was acceptably characterized in references [12,13], some differences with our experimental data were found and no crystallographic analysis was supplied. These findings encouraged us to grow crystals of chalcone 3 suitable for X-ray diffraction. Additionally, a complete analytical and spectroscopic characterization (i.e., IR, 1D and 2D NMR, mass and elemental analysis) of compound 3 was performed; see Materials and Methods section.

\subsection{Structural Analysis}

Single crystals of 3 suitable for X-ray diffraction were grown via slow evaporation in ethanol at room temperature. According to the results (Figures 1 and 2 and Tables 1 and 2), there is no doubt that the obtained compound effectively corresponds to chalcone 3 as suggested in Scheme 1, (Entry 3). 


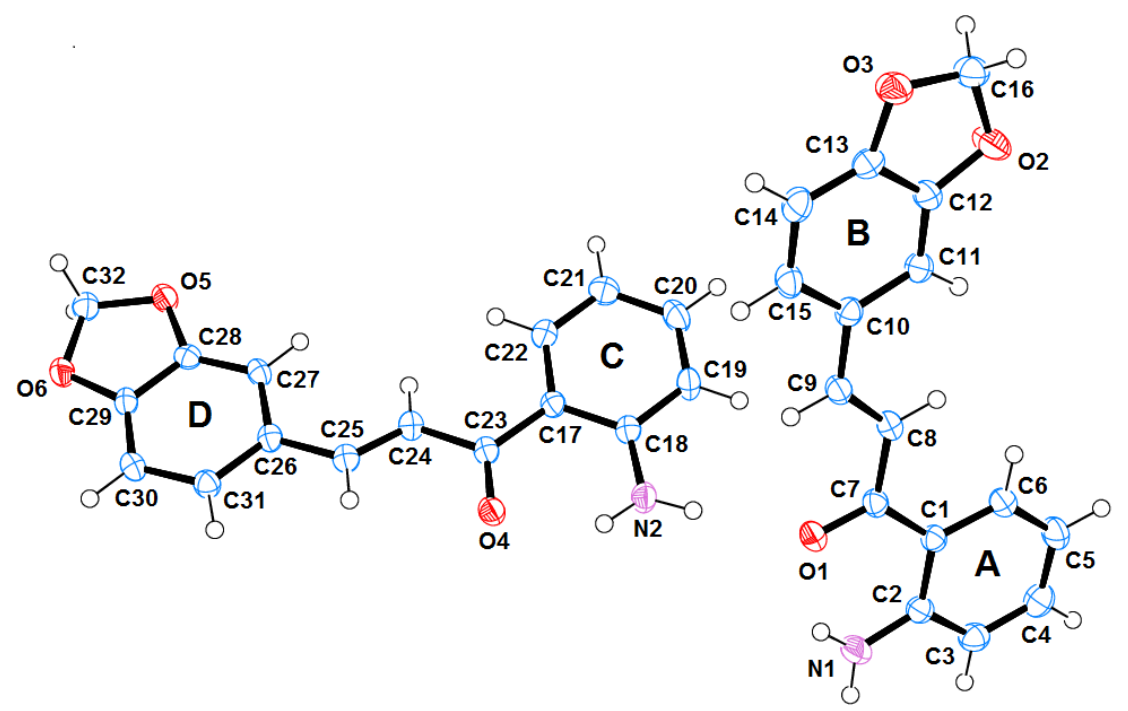

Figure 1. Oak Ridge Thermal Ellipsoids Program (ORTEP) drawing of the asymmetric unit for the $o$-aminochalcone 3; ellipsoids are displayed at the $50 \%$ probability level.

Table 1. Selected bond lengths $[\AA]$, angles $\left[{ }^{\circ}\right]$ and torsion angles $\left[{ }^{\circ}\right]$ for chalcone 3 .

\begin{tabular}{|c|c|}
\hline \multicolumn{2}{|c|}{ Bond Lengths } \\
\hline C1-C7; 1.4696(18) & C17-C23; 1.4712(18) \\
\hline C7-O1; 1.2445(16) & C23-O4; 1.2431(16) \\
\hline C8-C9; 1.3334(19) & C24-C25; $1.3322(19)$ \\
\hline C9-C10; 1.4553(19) & C25-C26; 1.4570(18) \\
\hline C10-C15; $1.3949(18)$ & С26-C31; $1.3966(18)$ \\
\hline O2-C12; 1.3608(17) & O5-C28; 1.3691(16) \\
\hline O3-C13; 1.3662(17) & O6-C29; 1.3663(16) \\
\hline C11-C12; 1.3591(19) & C27-C28; 1.3611(19) \\
\hline $\mathrm{C} 13-\mathrm{C} 14 ; 1.363(2)$ & С29-С $30 ; 1.3647(19)$ \\
\hline \multicolumn{2}{|c|}{ Angles } \\
\hline C7-C8-C9; 122.35(13) & C17-C23-C24; 119.00(12) \\
\hline C8-C9-C10; 126.41(13) & C24-C25-C26; 126.36(13) \\
\hline \multicolumn{2}{|c|}{ Torsion Angles } \\
\hline N1-C2-C1-C7; -2.2(2) & N2-C18-C17-C23;-0.57(18) \\
\hline C2-C1-C7-O1; 1.9(2) & C18-C17-C23-O4; 7.32(18) \\
\hline
\end{tabular}

Similar compounds to 3 have previously been reported in the literature (i.e., 1-(6-amino-1,3benzodioxol-5-yl)-3-(3,4,5-trimethoxyphenyl)prop-2-en-1-one [14] and 1-(6-amino-1,3-benzodioxol5-yl)-3-(4-methoxyphenyl)prop-2-en-1-one [15]). The title compound 3 crystallizes in triclinic, $P \overline{1}$, with $\mathrm{Z}=4$. In the molecular structure of 3 shown in Figure 1, the central fragments $\mathrm{C} 1-\mathrm{C} 7(\mathrm{O} 1)-\mathrm{C} 8=\mathrm{C} 9-\mathrm{C} 10$ and $\mathrm{C} 17-\mathrm{C} 23(\mathrm{O} 2)-\mathrm{C} 24=\mathrm{C} 25-\mathrm{C} 6$ are essentially planar (root-mean-square (r.m.s.) deviation for all non- $\mathrm{H}$ atoms $=0.0210 \AA$ and $0.0493 \AA$ respectively) and they form dihedral angles of $1.47(9)^{\circ}$ and $7.79(15)^{\circ}$ with the $\mathrm{A}$ and $\mathrm{C}$ aryl rings, respectively and $4.86(9)^{\circ}$ and $2.09(15)^{\circ}$ with the $\mathrm{B}$ and D benzodioxol rings, respectively. The amino groups are syn positioned with respect to the carbonyl groups in both molecules.

Bond lengths and bond angles in the title molecules are in good agreement with those found in the related compounds of the references [14,15], with the exception of the C10-C15 and C26-C31 bond lengths. Whereas the title structure exhibits shortened distances of 1.3949(18) and 1.3966(18) $\AA$, respectively, in these compounds, such bond lengths are 1.426(3) and 1.430(3) $\AA$, respectively. 


\subsection{Supramolecular Features}

The packing arrangement of the title compound can be described by strong intramolecular $\mathrm{N}-\mathrm{H} . . . \mathrm{O}$ hydrogen bonds and by intermolecular $\mathrm{N}-\mathrm{H} . . . \mathrm{O}$ and $\mathrm{C}-\mathrm{H} . . . \mathrm{O}$ hydrogen bonds of medium-strength (see Table 1), [16]. The two molecules of the asymmetric unit intertwine to form intra-intermolecular intercalated bonds, generating $S(6)$ and $R_{4}^{4}(24)$ rings [17]. In these interactions, the N2-H3N moiety in the molecule at $(x, y, z)$ acts as a hydrogen-bond donor to the $\mathrm{O} 1$ atom of the carbonyl group at $(\mathrm{x}, \mathrm{y}, \mathrm{z})$ and $\mathrm{N} 1-\mathrm{H} 1 \mathrm{~N}$ in the molecule at $(\mathrm{x}, \mathrm{y}, \mathrm{z})$ acts as a hydrogen-bond donor to the $\mathrm{O} 4$ atom of the carbonyl group at $(2-\mathrm{x}, 1-\mathrm{y}, 1-\mathrm{z})$. Molecules are connected and they are related by an inversion center, forming a kind of inner ring as seen in Figure 2. One of the molecules of the asymmetric unit proceeds to join, via C32-H32...O5 bonds with its twin molecule, configuring dimers with $R_{2}^{2}-(6)$ rings. Thus, the inner rings are attached to $\mathrm{C}(18)$ chains of molecules, forming sheets running parallel to (110).

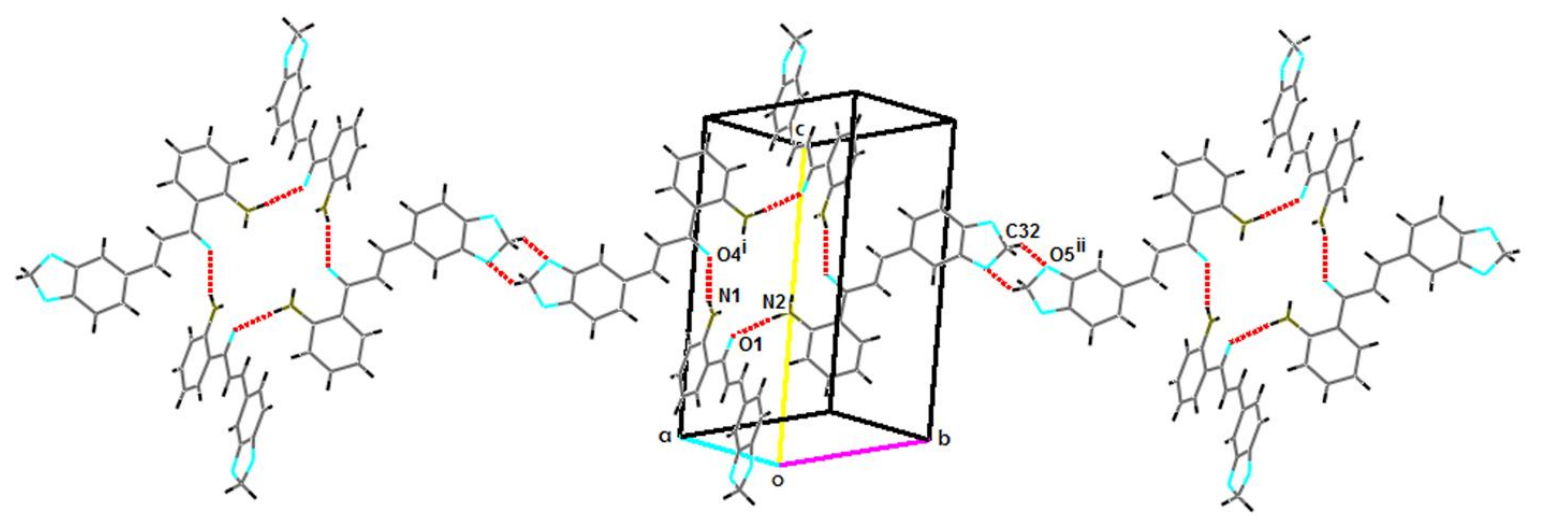

Figure 2. Part of the crystal structure of 3, showing the formation of $\mathrm{S}(6), R_{2}^{2}(6)$ and $R_{4}^{4}$-(24) rings along with $C(18)$ chains running parallel to (010). (Symmetry codes: (i) $2-x, 1-y, 1-z$; (ii) $-x, 3-y$, $1-\mathrm{z})$.

Table 2. Hydrogen bond lengths $[\AA]$ and angles $\left[{ }^{\circ}\right]$ for $o$-aminochalcone 3 .

\begin{tabular}{ccccc}
\hline D-H...A & D-H & H...A & D...A & D-H...A \\
\hline N2-H3N . . O1 & $0.899(18)$ & $2.132(19)$ & $3.0293(16)$ & $175.8(16)$ \\
N1-H1N . . O44 $4^{\mathrm{i}}$ & $0.88(2)$ & $2.22(2)$ & $3.0254(17)$ & $152.6(16)$ \\
C32-H32B . . O O ${ }^{\mathrm{ii}}$ & 0.99 & 2.49 & $3.3497(17)$ & 144.9 \\
\hline \multicolumn{5}{c}{ Symmetry codes: (i) 2-x, 1- y, 1- z; (ii) $-\mathrm{x}, 3-\mathrm{y}, 1-\mathrm{z}}$.
\end{tabular}

\section{Materials and Methods}

\subsection{General Information}

The melting point was determined on a Büchi melting point B-450 apparatus (Instrumart, South Burlington, VT, USA) and is uncorrected. The FTIR spectrum was recorded on a Shimadzu FTIR 8400 spectrophotometer (Scientific Instruments Inc., Seattle, WA, USA) using $\mathrm{KBr}$ disks. ${ }^{1} \mathrm{H}$ - and ${ }^{13} \mathrm{C}-\mathrm{NMR}$ spectra were recorded on a Bruker Avance 400 spectrometer (Bruker BioSpin GmbH, Rheinstetten, Germany) operating at $400 \mathrm{MHz}$ and $100 \mathrm{MHz}$, respectively, and using DMSO- $d_{6}$ as solvent and tetramethylsilane as an internal standard. The mass spectrum was obtained on a SHIMADZU-GCMS 2010-DI-2010 spectrometer (Scientific Instruments Inc., Columbia, IN, USA), equipped with a direct inlet probe) operating at $70 \mathrm{eV}$. Microanalysis was performed on a Thermo-Finnigan Flash EA1112 CHN elemental analyzer (Thermo Fischer Scientific Inc., Madison, WI, USA), and the values are within $\pm 0.4 \%$ of the theoretical values. Silica gel aluminum plates (Merck $60 \mathrm{~F}_{254}$, Darmstadt, Germany) were used for analytical Thin Layer Chromatography (TLC). The starting ketone $\mathbf{1}$ and aldehyde $\mathbf{2}$ were 
purchased from (Sigma-Aldrich, San Luis, MO, USA); analytical or reagent grades were used without further purification.

\subsection{Synthesis of (E)-1-(2-Aminophenyl)-3-(benzo[d][1,3]dioxol-5-yl)prop-2-en-1-one (3)}

A mixture of $o$-aminoacetophenone $1(0.5 \mathrm{~g}, 1 \mathrm{mmol})$, piperonal $2(1 \mathrm{mmol}), 20 \% \mathrm{NaOH}$ aqueous solution $(0.5 \mathrm{~mL})$, and $96 \% \mathrm{EtOH}(5 \mathrm{~mL})$ was subjected to reflux for $20 \mathrm{~min}$. The solid formed was filtered and washed with water then with ethanol. Recrystallization from $96 \%$ ethanol afforded 3 (76\% ield, yellow solid, m.p. $\left.117^{\circ} \mathrm{C}\right)$. FTIR (KBr): $v=3425,3309\left(\mathrm{NH}_{2}\right), 3070,2904,1633(\mathrm{C}=\mathrm{O})$, 1601, 1566, 1244 and 1207 (CO) $\mathrm{cm}^{-1} .{ }^{1} \mathrm{H}-\mathrm{NMR}\left(400 \mathrm{MHz}, \mathrm{DMSO}-d_{6}\right) \delta: 6.11\left(\mathrm{~s}, 2 \mathrm{H}, \mathrm{OCH}_{2} \mathrm{O}, \mathrm{H}-16\right)$, $6.60(\mathrm{t}, J=8.0 \mathrm{~Hz}, 1 \mathrm{H}, \mathrm{H}-5), 6.81(\mathrm{~d}, J=8.0 \mathrm{~Hz}, 1 \mathrm{H}, \mathrm{H}-3), 6.98(\mathrm{~d}, J=8.0 \mathrm{~Hz}, 1 \mathrm{H}, \mathrm{H}-14), 7.26-7.29(\mathrm{~m}, 2 \mathrm{H}$, H-15, H-4), 7.38 (s, 2H, NH $)_{2}, 7.59$ (d, J = 16.0 Hz, 1H, H-9), 7.63 (s, 1H, H-11), $7.84(\mathrm{~d}, J=16.0 \mathrm{~Hz}$, $1 \mathrm{H}, \mathrm{H}-8), 8.11(\mathrm{~d}, J=8.0 \mathrm{~Hz}, 1 \mathrm{H}, \mathrm{H}-6) \mathrm{ppm} .{ }^{13} \mathrm{C}-\mathrm{NMR}\left(100 \mathrm{MHz}, \mathrm{DMSO}-d_{6}\right) \delta: 102.0\left(\mathrm{C}-16, \mathrm{OCH}_{2} \mathrm{O}\right)$, 107.4 (C-11), 108.9 (C-14), 114.9 (C-5), 117.3 (C-3), 118.2 (C-2), 121.8 (C-8), 125.8 (C-15), 130.1 (C-1), 131.9 (C-6), 134.6 (C-4), 142.5 (C-9), 148.6 (C-12), 149.6 (C-13), 152.5 (C-10), 191.0 (C-7, C=O) ppm. The numbering of the $\mathrm{C}$ and $\mathrm{H}$ atoms is the same as that for structure 3 in Figure 1. Anal. calcd. for $\mathrm{C}_{16} \mathrm{H}_{13} \mathrm{NO}_{3}$ (267.27): $\mathrm{C}, 71.90 ; \mathrm{H}, 4.90 ; \mathrm{N}$, 5.24. Found: $\mathrm{C}, 72.03 ; \mathrm{H}, 4.77 ; \mathrm{N}, 5.35$. MS (EI, $\left.70 \mathrm{eV}\right) \mathrm{m} / z(\%)$ : $267(31)\left[\mathrm{M}^{+}\right], 266(50), 146(100)$.

Crystal Data: $\mathrm{C}_{16} \mathrm{H}_{13} \mathrm{NO}_{3}(\mathrm{M}=267.27 \mathrm{~g} / \mathrm{mol})$ : triclinic, space group $P \overline{1}$ (no. 2), a = 7.7323(3) $\AA$, $\mathrm{b}=11.2145(5) \AA, \mathrm{c}=15.1819(7) \AA, \mathrm{V}=1276.36(10) \AA^{3}, \mathrm{Z}=4, \mathrm{~T}=123(2) \mathrm{K}, \mu(\mathrm{MoK} \alpha)=0.097 \mathrm{~mm}^{-1}$, $\mathrm{D}_{\text {calc }}=1.391 \mathrm{Mg} / \mathrm{m}^{3}, 11,674$ reflections measured $\left(3.028^{\circ} \leq \theta \leq 27.497^{\circ}\right), 5794$ unique $\left(R_{\text {int }}=0.0185\right.$, $\left.R_{\text {sigma }}=0.0317\right)$ which were used in all calculations. The final R1 was $0.0413(\mathrm{I}>2 \sigma(\mathrm{I}))$ and $w R 2$ was 0.0554 (all data).

Data Collection and Refinement Details: Diffraction data were collected on an Oxford Diffraction Xcalibur E diffractometer [18], using graphite monochromated MoK $\alpha$ radiation (0.71073 $\AA$ ). The corrected data were solved by direct methods with SHELXS-97 and refined by full-matrix methods on $\mathrm{F}^{2}$ with SHELXL-2014 [19]. All H-atoms, except for $\mathrm{H}-\mathrm{N}$, were positioned at geometrically idealized positions, $\mathrm{C}-\mathrm{H}=0.9500 \AA, \mathrm{C} 16-\mathrm{H}=0.9900 \AA$ and $\mathrm{C} 32-\mathrm{H}=0.9900 \AA$ and were refined using a riding model approximation with $\mathrm{U}_{\text {iso }}(\mathrm{H})=1.2 \mathrm{U}_{\text {eq }}$ (parent atom). $\mathrm{H}-\mathrm{N}$ atoms were found from the Fourier difference maps, and their coordinates were freely refined. Correctness of the model was confirmed by low residual peaks $(0.257)$ and holes $\left(-0.203 \mathrm{e} . \AA^{-3}\right)$ in the final difference map. (CCDC 1518500 contains the supplementary crystallographic data for this paper. These data can be obtained free of charge via http://www.ccdc.cam.ac.uk/conts/retrieving.html or from the CCDC, 12 Union Road, Cambridge CB2 1EZ, UK; Fax: +44 1223 336033; E-mail: deposit@ccdc.cam.ac.uk.)

Supplementary Materials: Copies of the IR, ${ }^{1} \mathrm{H}-,{ }^{13} \mathrm{C}-\mathrm{NMR}$, DEPT-135, 2D NMR and mass spectra and the checkCIF and CIF files for compound 3 can be found at www.mdpi.com/1422-8599/2017/1/M924.

Acknowledgments: Authors thank COLCIENCIAS and Universidad del Valle for financial support-Project Number CI-7907. D.A. specially thank COLCIENCIAS for a "Joven Investigador" fellowship.

Author Contributions: R.A. designed the experiments; D.A. and D.I. performed the experiments; R.A., D.A., D.I., J.Q., and B.I. analyzed the IR, MS, and NMR spectral data and wrote the manuscript; R.M-F. and A.R.K. performed the measurement and analysis of the X-ray experiments and helped to write the manuscript. All authors read and approved the final manuscript.

Conflicts of Interest: The authors declare no conflict of interest.

\section{References and Note}

1. Pereira-Ávila, H.; de Albino-Smânia, E.F.; Delle-Monache, F.; Smânia-Júnior, A. Structure-activity relationship of antibacterial chalcones. Bioorg. Med. Chem. 2008, 16, 9790-9794. [CrossRef] [PubMed]

2. Sivakumar, P.M.; Muthu-Kumar, T.; Doble, M. Antifungal activity, mechanism and QSAR studies on chalcones. Chem. Biol. Drug Des. 2009, 74, 68-79. [CrossRef] [PubMed] 
3. Modzelewska, A.; Pettit, C.; Achanta, G.; Davidson, N.E.; Huang, P.; Khan, S.R. Anticancer activities of novel chalcone and bis-chalcone derivatives. Bioorg. Med. Chem. 2006, 14, 3491-3495. [CrossRef] [PubMed]

4. Won, S.-J.; Liu, C.-T.; Tsao, L.-T.; Weng, J.-R.; Ko, H.-H.; Wang, J.-P.; Lin, C.-N. Synthetic chalcones as potential anti-inflammatory and cancer chemopreventive agents. Eur. J. Med. Chem. 2005, 40, 103-112. [CrossRef] [PubMed]

5. Elarfi, M.J.; Al-Difar, H.A. Synthesis of some heterocyclic compounds derived from chalcones. Sci. Revs. Chem. Commun. 2012, 2, 103-107.

6. Kalirajan, R.; Sivakumar, S.U.; Jubie, S.; Gowramma, B.; Suresh, B. Synthesis and biological evaluation of some heterocyclic derivatives of chalcones. Int. J. ChemTech Res. 2009, 1, 27-34.

7. Bandgar, B.P.; Patil, S.A.; Gacche, R.N.; Korbad, B.L.; Hote, B.S.; Kinkar, S.N.; Jalde, S.S. Synthesis and biological evaluation of nitrogen-containing chalcones as possible anti-inflammatory and antioxidant agents. Bioorg. Med. Chem. Lett. 2010, 20, 730-733. [CrossRef] [PubMed]

8. Gabrielsen, B.; Monath, T.; Huggins, J.; Kefauver, D.; Pettit, G.; Groszek, G.; Hollingshead, M.; Kirsi, J.; Shannon, W.; Schubert, E.M.; et al. Antiviral (RNA) activity of selected amaryllidaceae isoquinoline constituents and synthesis of related substances. J. Nat. Prod. 1992, 55, 1569-1581. [CrossRef] [PubMed]

9. Krause, W.; Goeber, B. Spasmolytic effects of tetrahydroisoquinoline derivatives. Pharmazie 1972, 27, 419-420. [PubMed]

10. Abonia, R.; Cuervo, P.; Insuasty, B.; Quiroga, J.; Nogueras, M.; Cobo, J.; Meier, H.; Lotero, E. An Amberlyst-15 ${ }^{\circledR}$ mediated synthesis of new functionalized dioxoloquinolinone derivatives. Open Org. Chem. J. 2008, 2, $26-34$. [CrossRef]

11. Abonia, R.; Cuervo, P.; Insuasty, B.; Quiroga, J.; Nogueras, M.; Cobo, J. A simple two-step sequence for the synthesis of novel 3-aryl[1,3]dioxolobenzo[f]pyrrolo[1,2-a]azepin-11-ones from 6-amino-3,4methylenedioxyacetophenone. Eur. J. Org. Chem. 2008, 4684-4689. [CrossRef]

12. Tókés, A.L.; Forró, I. Bromo-derivatives of 2'-NHR-3,4-methylenedioxychalcone and its 4-quinolone isomer. Synth. Commun. 1991, 21, 1201-1211. [CrossRef]

13. Bunce, R.A.; Nammalwar, B. $( \pm)$-2-Aryl-2,3-dihydro-4(1H)-quinolinones by a tandem reduction-Michael addition reaction. J. Heterocyclic Chem. 2011, 48, 613-619. [CrossRef]

14. Low, J.N.; Cobo, J.; Nogueras, M.; Sánchez, A.; Albornoz, A.; Abonia, R. A comparison of the supramolecular structures of 1-(6-amino-1,3-benzo-dioxol-5-yl)-3-(3,4,5-trimethoxy-phenyl)prop-2-en-1-one and 1-(6-amino1,3-benzodioxol-5-yl)-3-[4-(N,N-dimethylamino)phenyl]-prop-2-en-1-one. Acta Cryst. 2002, C58, o42-o45.

15. Low, J.N.; Cobo, J.; Nogueras, M.; Cuervo, P.; Abonia, R.; Glidewell, C. Polarized molecular-electronic structures and supramolecular aggregation in 1-(6-amino-1,3-benzo-dioxol-5-yl)-3-arylprop-2-en-1-ones. Acta Cryst. 2004, C60, o744-o750.

16. Nardelli, M. PARST95-An update to PARST: A system of Fortran routines for calculating molecular structure parameters from the results of crystal structure analyses. J. Appl. Cryst. 1995, 28, 659. [CrossRef]

17. Etter, M. Encoding and decoding hydrogen-bond patterns of organic compounds. Acc. Chem. Res. 1990, 23, 120-126. [CrossRef]

18. Oxford Diffraction CrysAlis PRO. 2010, Oxford Diffraction Ltd., Yarnton, England.

19. Sheldrick, G.M. Crystal structure refinement with SHELXL. Acta Cryst. 2015, C71, 3-8.

(C) 2016 by the authors; licensee MDPI, Basel, Switzerland. This article is an open access article distributed under the terms and conditions of the Creative Commons Attribution (CC-BY) license (http://creativecommons.org/licenses/by/4.0/). 